\title{
Preparation of pilot-scale inner skin hollow fiber pervaporation membrane module: Effects of dynamic assembly conditions
}

\author{
Guojun Zhang ${ }^{\mathrm{a}, *}$, Naixin Wang ${ }^{\mathrm{a}}$, Xue Song ${ }^{\mathrm{a}}$, Shulan $\mathrm{Ji}^{\mathrm{a}, *}$, Zhongzhou Liu $^{\mathrm{b}}$ \\ a Center for Membrane Technology, College of Environmental and Energy Engineering, Beijing University of Technology, Beijing 100124, PR China \\ ${ }^{\mathrm{b}}$ Research Center for Eco-Environmental Sciences, Chinese Academy of Sciences, Beijing 100085, PR China
}

\section{A R T I C L E I N F O}

\section{Article history:}

Received 3 February 2009

Received in revised form 21 March 2009

Accepted 2 April 2009

Available online 11 April 2009

\section{Keywords:}

Hollow fiber

Pervaporation

Polyelectrolyte multilayer membranes

Packing density

Dynamic negative pressure layer-by-layer process

\begin{abstract}
A B S T R A C T
The purpose of this study is to provide some fundamental understanding for the design of industrial hollow fiber pervaporation membrane module. Inner skin hollow fiber pervaporation membrane modules were fabricated by a dynamic negative pressure layer-by-layer (LbL) technique. The influences of dynamic negative pressure and recycling velocity of polyelectrolyte solutions on the formation of non-porous selective layer were firstly investigated using mini-modules during the dynamic assembly process. Since none of reported works dealt with the effects of packing density of hollow fiber module, pilot-scale modules (diameter $\times$ length $=1 \mathrm{in} . \times 20 \mathrm{~cm}$ ) were therefore prepared by filling different amounts of hollow fibers into a membrane shell. The experimental results show that the higher packing density of $500 \mathrm{~m}^{2} / \mathrm{m}^{3}$ rendered both total flux and selectivity to decrease significantly. As for a $1 \mathrm{~m}$ long module that has been commonly used in industry, further investigations were conducted using a 1-m long hollow fiber module. The vacuum drop along the axial direction of hollow fibers was noted, especially near to the vacuum suction opening. Despite of this, the relatively high and stable selectivity could be obtained even the fiber length increased to $1 \mathrm{~m}$.
\end{abstract}

(C) 2009 Elsevier B.V. All rights reserved.

\section{Introduction}

Pervaporation (PV) is becoming one of the key technologies for the separation of azeotropic, close boiling, isomeric or heatsensitive liquid mixtures. However, pervaporation is less familiar to the industry in comparison to the well-established pressuredriven membrane processes such as microfiltration, ultrafiltration, nanofiltration and reverse osmosis. The central part of any membrane plant is the module, i.e. the technical arrangement of the membranes [1]. The plate-and-frame is still the dominating module configuration employed in pervaporation since this configuration can provide low resistance channels in both permeate and feed side. The ease in manufacturing is also one of the factors accounting for the dominance [2]. In contrast with plate-and-frame membranepacking configurations, relatively few papers have been reported on the application of hollow fiber membranes in pervaporation because of complexities and difficulties in manufacturing hollow fiber-based pervaporation modules. However, development of asymmetric hollow fiber module for pervaporation applications has recently attached increasingly interests due to its some advantages such as high packing density, a self-supporting structure, a self-

\footnotetext{
* Corresponding authors. Tel.: +86 1067392961 ; fax: +86 1067391983 .

E-mail addresses: zhanggj@bjut.edu.cn (G. Zhang), jshl@bjut.edu.cn (S. Ji).
}

contained vacuum channel and hence the consequent economical superiority [3-8].

In order to successfully develop asymmetric hollow fibers for pervaporation, the construction of selective layer with superior performance and minimal solvent-induced swelling is very crucial. Most of the previous studies made great efforts to fabricate the ultra-thin defect-free selective layer onto the outer surface of hollow fiber supports [3-8]. In this type of module, a feed was commonly supplied from the shell side while vacuum was applied on the lumen side. As a comparison, little attention has been paid to the inner skin hollow fiber pervaporation membrane module. Actually, in pervaporation module design, it is a critical consideration to ensure low transport resistance in the permeate side because the efficient evaporation of the permeate molecules in the downstream face of the membrane needs an extremely low absolute pressure [2]. Therefore, one of the most important problems is to reasonably arrange vacuum channel for the hollow fiber pervaporation module. When lumen side was used as a vacuum channel, the presence of resistance in the permeate channel might very sensitively affect the pervaporation separation process since the lumen side space is very limited and strongly depends on the fiber diameters. Zhou and Koros' study indicated that the fiber bore size has a significant influence on pervaporation performance of hollow fiber module since the fiber bore size affected the bore pressure change along the axial direction of hollow fibers [8]. Shao et al. have also ever pointed out that it is impossible for a hollow fiber module to be employed in 
pervaporation unless the fiber length is improperly short, or the fiber diameter is big enough, e.g., 5-25 mm [2,9]. Since the shell side space could be flexibly adjusted, it was thought that the adoption of shell side as downstream side might easily form the high vacuum channel and reduce the resistance in the permeate side. In this case, the fabrication of selective layer on the inner surface of hollow fibers was required. Additionally, inner skin hollow fiber module could effectively protect separation layer, which is very important for pervaporation process to avoid the formation of the defects and destroying the separation layer caused by the external factors. Therefore, preparation of inner skin hollow fiber module, especially for the industrial module, is of particular interest for pervaporation separation processes. However, it is relatively difficult to obtain a uniform and defect-free inner skin on the hollow fiber using the conventional dip-coating method. We had successfully prepared inner skin hollow fiber module for pervaporation dehydration by using a dynamic negative pressure layer-by-layer (LbL) technique [10]. This method is based on the alternatively deposition of oppositely charged polyelectrolytes onto inner surface of hollow fiber supports by a pressure-driven process. The dynamic negative pressure LbL has proved to be a promising technique for the assembly hollow fiber membrane module. It was noted from the previous study that increasing number of deposited bilayers had a great influence on both flux and selectivity of the composite membranes [10]. However, some important aspects include dynamic negative pressure and recycling velocity of polyelectrolyte solutions should also be taken into consideration. Therefore, the effects of dynamic assembly conditions on the pervaporation performance of the module were further investigated in this study. Furthermore, the effects of packing density and fiber length on pervaporation performance are currently still unknown for the hollow fiber module design. Hence, in the present work, pilot-scale membrane modules were also prepared to better understand the contributions of these factors for the preparation of hollow fiber module. It was expected the fundamental understanding obtained from this study would be useful for the design and scale-up of industrial hollow fiber pervaporation membrane module.

\section{Experimental}

\subsection{Materials}

The polyacrylic acid (PAA) powder having average molecular weight of 4,000,000 and branched poly(ethyleneimine) (PEI) with the molecular weight of 60,000 were obtained from Aldrich and ACROS, respectively. Sodium hydroxide and ethanol were provided by Beijing Chemical Factory. The hollow fiber support membranes were produced by the phase inversion method from polyacrylonitrile (PAN) polymer in our workshop [11]. The inner diameter of each hollow fiber was $1.1 \mathrm{~mm}$.

\subsection{Preparation of mini- and pilot-scale hollow fiber module}

For the preparation of mini-module, the PAN fibers with an effective length of $15 \mathrm{~cm}$ were firstly hydrolyzed by immersing into the aqueous solutions of sodium hydroxide under the temperature of $60^{\circ} \mathrm{C}$. After hydrolyzing for $15 \mathrm{~min}$, the membranes was taken out and rinsed with de-ionized water until the $\mathrm{pH}$ values of the rinsed water reached about 7.0. These fibers were then put into a polymethylmethacrylate tube with a diameter of $1.5 \mathrm{~cm}$. Both ends of the module were sealed with epoxy resin. After $24 \mathrm{~h}$ for the epoxy to get cured, the mini-modules were mounted on the dynamic filtration system for assembly. To prepare pilot-scale modules, a bundle of individual fibers were packed into a membrane shell. The hydrolysis was then conducted by recycling aqueous solutions of sodium hydroxide with a peristaltic pump. The hydrolysis temperature was also controlled at $60^{\circ} \mathrm{C}$. As previously reported [10], the preparation of hollow fiber membrane modules was carried out by using a laboratory fabricated cross-flow filtration cell. The PAA and PEI solutions were alternatively provided into the inner channel of hollow fiber and then recycled by using two peristaltic pumps and through separate tubings. On the shell side, a vacuum pump was used to form a negative pressure. The assembly was carried out at room temperature. The repeating steps such as polyelectrolyte deposition, rinsing, and drying were the same as previously reported [10]. After each deposition, the membrane was rinsed with de-ionized water for twice. Nitrogen gas was then put into the inner channels to remove the water remained. After that, the membrane was dried in an oven at $50{ }^{\circ} \mathrm{C}$. In the present study, in order to verify the effects of packing density, a series of pilot-scale modules with the diameter $(\Phi)$ of 1 in. and the length $(L)$ of $20 \mathrm{~cm}$ were fabricated. The packing densities including $100,200,300,400$ and $500 \mathrm{~m}^{2} / \mathrm{m}^{3}$ was adjusted by packing different amounts of hollow fibers into the vessels. To ensure the uniformly deposition along the fiber length, the polyelectrolyte solutions were alternatively fed into hollow fibers at an interval of 5 min between two alternations of feed direction.

\subsection{Pervaporation experiments}

The mini- and pilot-scale modules were mounted onto a laboratory fabricated pervaporation system. The feeding solution contacted with the inner surfaces of the hollow fiber modules at $50^{\circ} \mathrm{C}$. Three modules with same fabrication and modification conditions were examined for each pervaporation condition. The permeate vapour was trapped with liquid nitrogen. The downstream pressure was about $100 \mathrm{~Pa}$. Fluxes were determined by measuring the weight of liquid collected in the cold traps during a certain time under steady-state conditions. The compositions of feeding solutions and permeates were determined with a gas chromatography (GC-14C, SHIMADZU). The separation factor was calculated from the quotient of the weight ratio of water and alcohol in the permeate, $Y_{\mathrm{HOH}} / Y_{\mathrm{ROH}}$, and in the feed, $X_{\mathrm{HOH}} / X_{\mathrm{ROH}}$ :

$\alpha=\frac{Y_{\mathrm{HOH}} / Y_{\mathrm{ROH}}}{X_{\mathrm{HOH}} / X_{\mathrm{ROH}}}$

\subsection{Measurement of vacuum drop along the axial direction of hollow fibers}

To simulate the industrial module and investigate the effects of fiber length on membrane performance, $1 \mathrm{~m}$ long hollow fiber pervaporation modules were prepared. As shown in Fig. 1, seven vacuum suction openings were designed along the axial direction of hollow fibers. The distance between each two neighboring openings was $15 \mathrm{~cm}$. A differential vacuum pressure gauge (SD-20, Summit, USA) was used to measure the vacuum drop along the axial direction of hollow fibers. There were two operation models. In model 1 , one of the contact points of differential vacuum pressure gauge was always fixed at opening 1 while the other contact point was moved from opening 2 to opening 7. By this way, the vacuum drop between opening 1 and openings 2-7 was determined. In model 2, the middle opening (opening 4) was used as a fixed contact points where the other contact point changed from opening 1 to opening 3 and then from opening 5 to opening 7 . The vacuum drops between opening 4 with the other openings were therefore determined.

\subsection{FESEM experiments}

A scanning electron microscopy (SEM) (Hitachi-4700, Japan) was used to observe the inner surface, cross-section and outer surface of hollow fiber membranes obtained. All membrane samples 


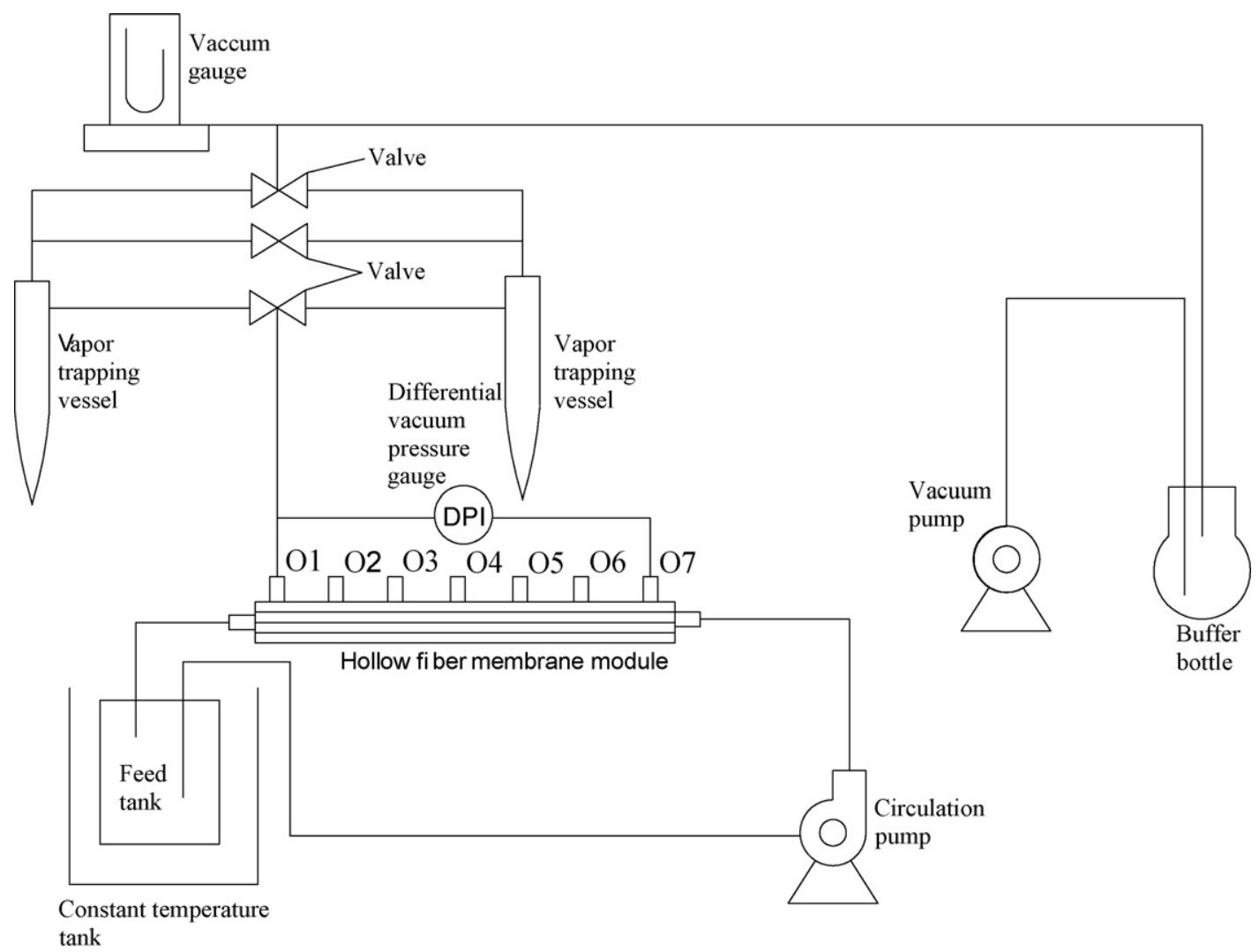

Fig. 1. Experimental apparatus for pervaporation evaluation of $1 \mathrm{~m}$ long hollow fiber membrane module.

were dried under vacuum, fractured in liquid nitrogen and goldcoated before observation.

\section{Results and discussion}

\subsection{Effects of dynamic negative pressure}

The pervaporation separation governed by a solution-diffusion mechanism requires the membrane to be non-porous [2]. The recently developed technique of dynamic negative LbL adsorption in our laboratory provides a particularly effective method for fabricating an ultrathin non-porous layer on the inner surface of hollow fiber support [10]. Since the non-porous selective layer was formed under a pressure-driven process, the effects of negative pressure on membrane performance were investigated from $-0.02 \mathrm{MPa}$ to $-0.08 \mathrm{MPa}$. The results are shown in Fig. 2 .

As shown in Fig. 2, when the negative pressure increased from $-0.02 \mathrm{MPa}$ to $-0.08 \mathrm{MPa}$, the separation factor improved while the permeation flux gradually decreased. During the assembly process, the polyelectrolyte multilayers are dynamically deposited on porous supports. Each added polyelectrolyte layer is used to cover the defects in prior layers. It is well known that ultrafiltration support membranes have a relatively wide pore diameter distribution. To obtain an integrated and defect-free selective layer for pervaporation membrane, it is vital to completely cover all underlying pores. Under the higher negative pressure, the large pores could much more easily be sealed due to the aggregation of polyelectrolyte complexes. Furthermore, the polyelectrolyte multilayers would become thicker and denser, which would lead to much higher separation factor. For example, the separation factor obtained from $-0.02 \mathrm{MPa}$ was 104 . As a comparison, this value could reach 1036 when the negative pressure was $-0.08 \mathrm{MPa}$. Additionally, since the thin separation layer provides most of the resistance to mass transport, flux is inversely proportional to the thickness of this layer for diffusionbased processes [12]. Therefore, it was noted that the flux decreased with the increase in the dynamic negative pressure. Fig. 3 shows the SEM of inner surfaces, typical cross-section and outer surface of the hollow fiber membranes. Comparing Fig. 3(a) with (b), (c) and (d), it was noted that the inner surface became denser and more compact with the increase in dynamic negative pressure. Additionally, the inner surface became non-porous while the outer surface still remain porous since the polyelectrolytes were mostly retained onto the inner surface of hollow fiber supports. Therefore, the asymmetrical structure pervaporation membranes were successfully fabricated.

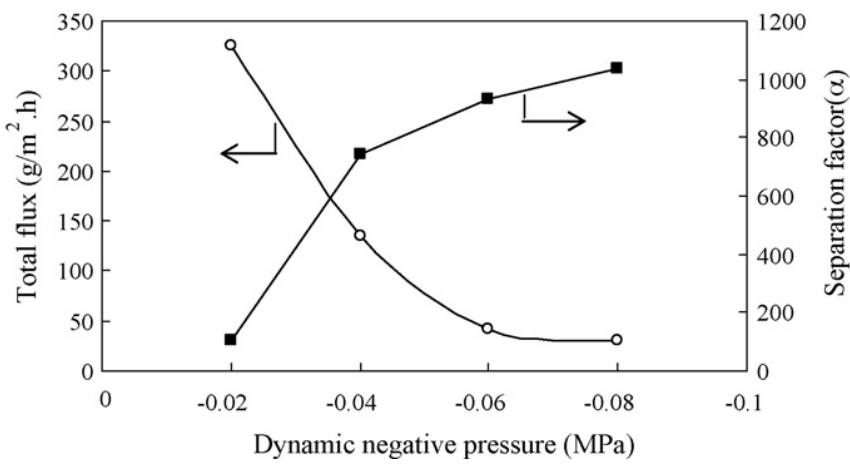

Fig. 2. Effects of dynamic nagative pressure on separation factor and flux. (Hydrolysis conditions for PAN support membrane: hydrolysis temperature $60^{\circ} \mathrm{C}$, hydrolysis time 15 min. Preparative conditions: 2.5 bilayers, recycling velocity of polyelectrolyte solutions $0.9 \mathrm{~m} / \mathrm{s} ; 30 \mathrm{~min}$ filtration time, packing density $150 \mathrm{~m}^{2} / \mathrm{m}^{3}$, PAA molecular weight $4,000,000,[\mathrm{PAA}]=0.05 \mathrm{wt} . \%,[\mathrm{PEI}]=0.25 \mathrm{wt} . \%$; pervaporation conditions: feed temperature $50{ }^{\circ} \mathrm{C}$, permeate pressure $100 \mathrm{~Pa}$, EtOH content in feed solution 95 wt.\%.) 
(a)

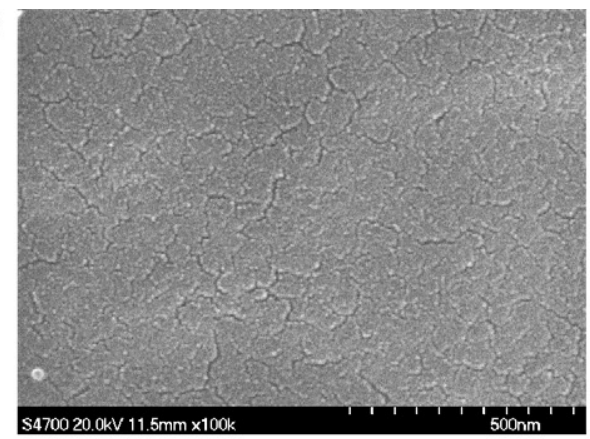

(c)

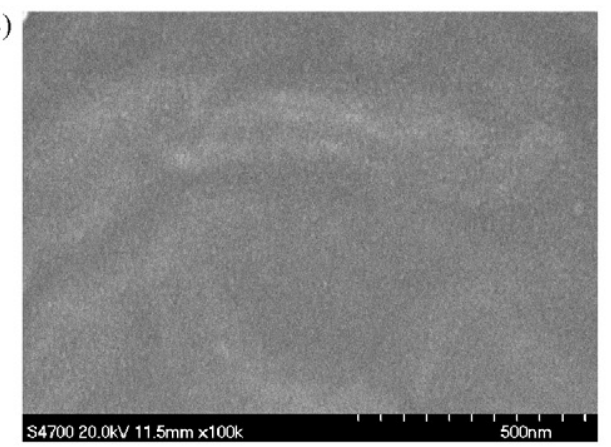

(e)

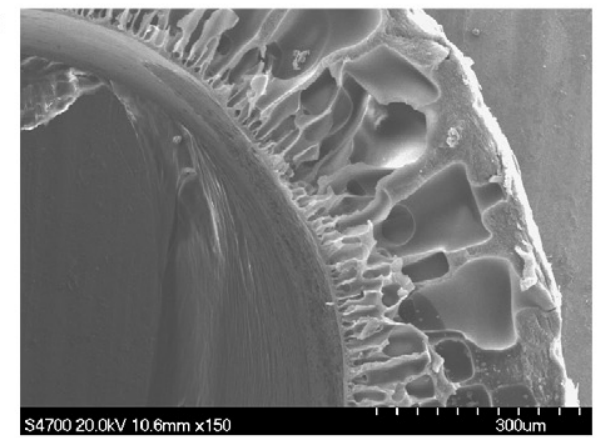

(b)

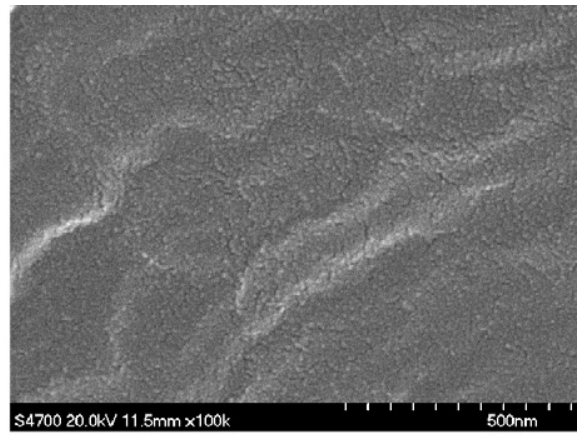

(d)

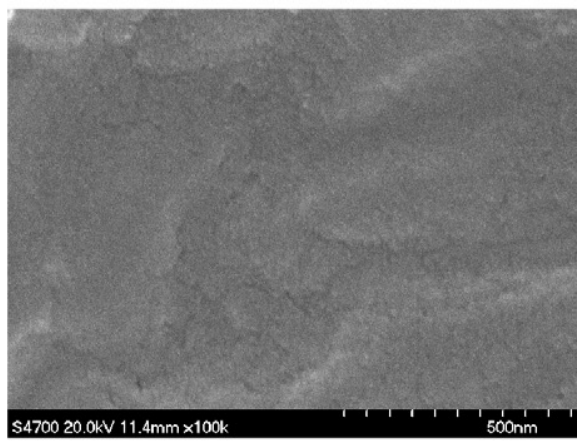

(f)

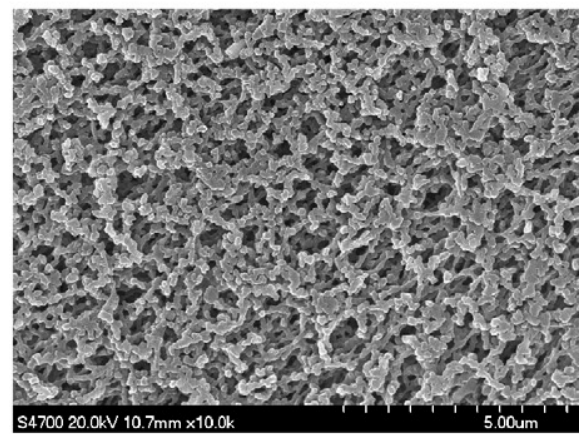

(g)

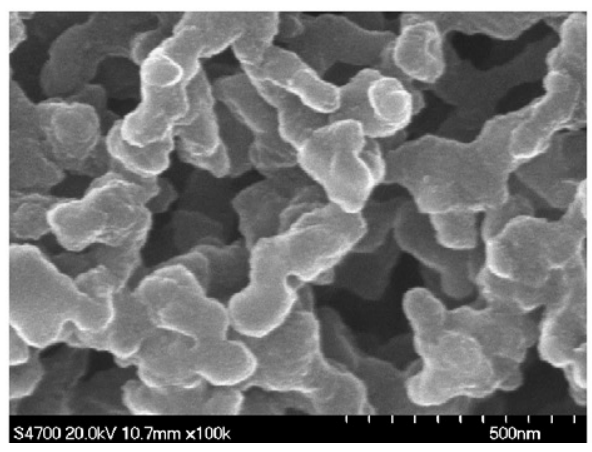

Fig. 3. SEM pictures of the hollow fiber pervaporation membrane assembled by dynamic negative pressure LbL technique. (a) Inner surface SEM (100.0k $\times$ ) (dynamic negative pressure $-0.02 \mathrm{MPa}$ ). (b) Inner surface SEM $(100.0 \mathrm{k} \times$ ) (dynamic negative pressure $-0.04 \mathrm{MPa})$. (c) Inner surface SEM (100.0k $\times$ ) (dynamic negative pressure $-0.06 \mathrm{MPa})$. (d) Inner surface SEM $(100.0 \mathrm{k} \times$ ) (dynamic negative pressure $-0.08 \mathrm{MPa}$ ). (e) Cross-sectional SEM of $150.0 \times$ (dynamic negative pressure $-0.04 \mathrm{MPa}$ ). (f) Outer surface SEM $(10.0 \mathrm{k} \times)$ (dynamic negative pressure $-0.04 \mathrm{MPa})$. (g) Outer surface SEM $(100.0 \mathrm{k} \times$ ) (dynamic negative pressure $-0.04 \mathrm{MPa})$. (Hydrolysis conditions for PAN support membrane: hydrolysis temperature $60^{\circ} \mathrm{C}$, hydrolysis time $15 \mathrm{~min}$. Preparative conditions: 2.5 bilayers, recycling velocity of polyelectrolyte solutions $0.9 \mathrm{~m} / \mathrm{s}$, packing density $150 \mathrm{~m}{ }^{2} / \mathrm{m}^{3}$, 30 min filtration time, $0.05 \mathrm{wt} . \%$ PAA aqueous solution, $0.25 \mathrm{wt} . \%$ aqueous PEI solution, $25^{\circ} \mathrm{C}$.)

\subsection{Effects of recycling velocity}

The deposition of polyelectrolyte pairs can be influenced by the shear induced at the hollow fiber membrane surface. Twelve smaller modules were in parallel prepared and used to investigate the effects of varying circulating velocity on membrane performance. As shown in Fig. 4, although the total fluxes increased from $59.4 \mathrm{~g} / \mathrm{m}^{2} \mathrm{~h}$ to $135.6 \mathrm{~g} / \mathrm{m}^{2} \mathrm{~h}$ when the circulating velocity of polyelectrolyte solution varied from $0 \mathrm{~m} / \mathrm{s}$ to $0.9 \mathrm{~m} / \mathrm{s}$, the sepa- ration factor decreased from 1564 to 741 . The reason was that the shear flow could possibly weaken the electrostatic adsorption between two oppositely charged polyelectrolytes. The higher circulating velocity and in turn the stronger shear, to some extent, could destroy the nascent selective layers, which would lead to the decline of selectivity. The SEM pictures in Fig. 5 also suggested that the low shear flow would benefit for the formation of uniform layer. For example, comparing Fig. 5(a) with (c) and (d), some of small creases on the inner surface were observed during the assembly with the 


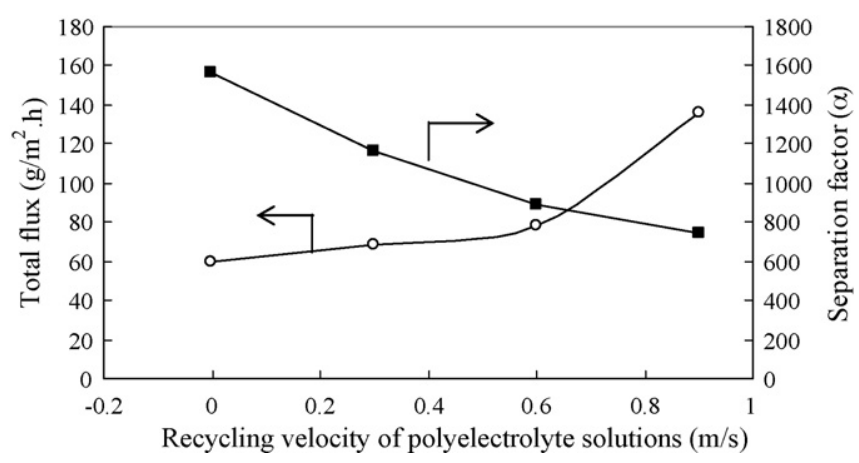

Fig. 4. Effects of recycling velocity of polyelectrolyte solutions on pervaporation performance of hollow fiber polyelectrolyte composite membranes. (Hydrolysis conditions for PAN support membrane: hydrolysis temperature $60^{\circ} \mathrm{C}$, hydrolysis time $15 \mathrm{~min}$. Preparative conditions: 2.5 bilayers, dynamic negative pressure $-0.04 \mathrm{MPa}$, packing density $150 \mathrm{~m}^{2} / \mathrm{m}^{3}, 30 \mathrm{~min}$ filtration time, $0.05 \mathrm{wt}$ \% PAA aqueous solution, 0.25 wt.\% aqueous PEI solution, $25^{\circ} \mathrm{C}$. Pervaporation conditions: feed temperature $50{ }^{\circ} \mathrm{C}$, down-stream pressure $100 \mathrm{~Pa}$, EtOH content in feed solution $95 \mathrm{wt} . \%$.)

relatively higher recycling velocities of polyelectrolyte solution. It should be pointed out that although the dead-end filtration (the circulating velocity was $0 \mathrm{~m} / \mathrm{s}$ ) of polyelectrolyte solution would lead to higher separation factor, we also observed that the fiber ends were easily blocked by the polyelectrolyte complexes precipitates formed due to the non-mobile polyelectrolyte solutions. Therefore, it is crucial to maintain the circulating velocity of polyelectrolyte solution within a relatively low range.

\subsection{Effects of packing density}

Pervaporation requires volatilization of a portion of liquid feed and then permeate vapour needs to be condensed in downstream side. The permeate vapour must be timely diffused and condensed to ensure the efficient separation. Otherwise, the downstream vapour would negatively affect the mass transport across perva-

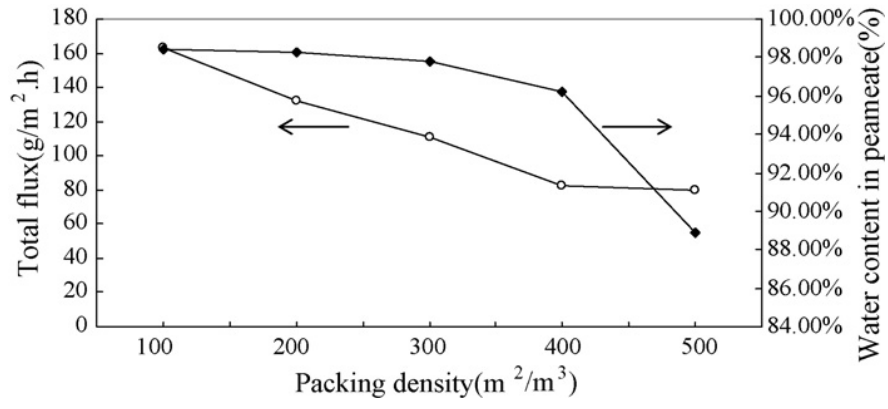

Fig. 6. Effects of packing density on pervaporation performance of polyelectrolyte composite membrane. (Hydrolysis conditions for PAN support membrane: hydrolysis temperature: $60^{\circ} \mathrm{C}$, hydrolysis time: $15 \mathrm{~min}$. Preparative conditions: 3.5 bilayers, dynamic negative pressure $-0.05 \mathrm{MPa}$, recycling velocity of polyelectrolyte solutions $0.3 \mathrm{~m} / \mathrm{s}, 30 \mathrm{~min}$ filtration time, $0.05 \mathrm{wt}$.\% PAA aqueous solution, $0.25 \mathrm{wt}$.\% aqueous PEI solution, $25^{\circ} \mathrm{C}$. Pervaporation conditions: feed temperature $50{ }^{\circ} \mathrm{C}$, down-stream pressure $100 \mathrm{~Pa}$, EtOH content in feed solution 95 wt.\%.)

poration membrane. Therefore, it was thought that the packing density might play an important role for the design of inner skin hollow fiber pervaporation module. However, none of reported works have previously dealt with the effects of packing density on the pervaporation performance of hollow fiber module. In this study, pilot-scale modules $(\Phi \times \mathrm{L}=1 \mathrm{in} . \times 20 \mathrm{~cm})$ were therefore prepared by filling different amounts of hollow fibers into a membrane shell. Fig. 6 shows the profiles of pervaporation membrane performance with packing density. It was noted that both total flux and selectivity were strongly dependent on the packing density. When the packing density was kept at the range of $100-300 \mathrm{~m}^{2} / \mathrm{m}^{3}$, the separation performance changed a little, the water content in the permeate still kept over $97.0 \%$. The water content in the permeate continued to decline to $96.2 \%$ and $88.9 \%$ as the packing density reached $400 \mathrm{~m}^{2} / \mathrm{m}^{3}$ and $500 \mathrm{~m}^{2} / \mathrm{m}^{3}$. It was also observed that the total flux always decreased sharply with the increase in the packing density. Obviously, the higher packing density would (a)

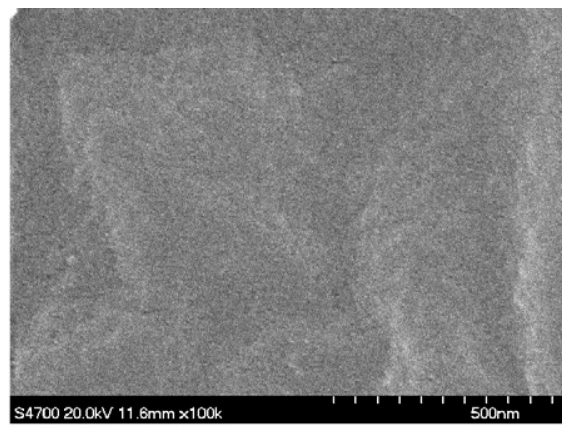

(c)

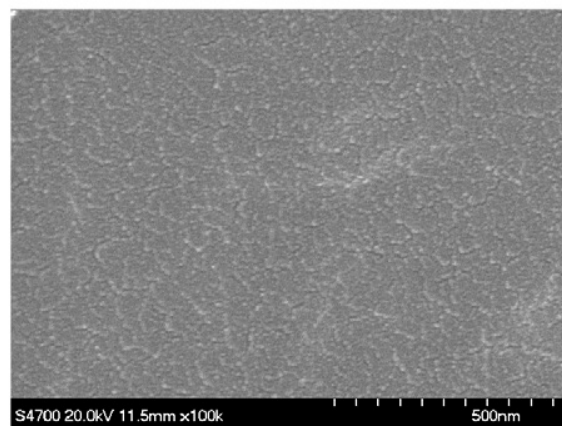

(b)

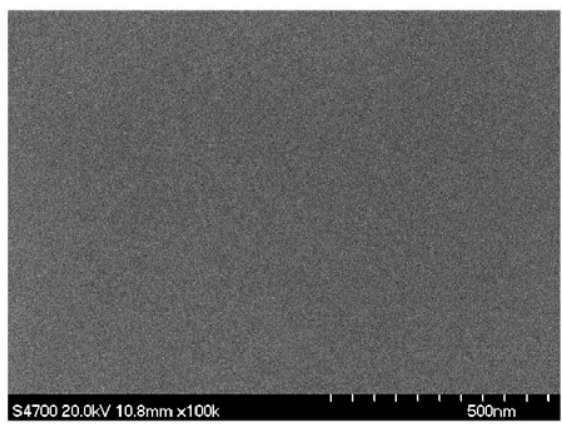

(d)

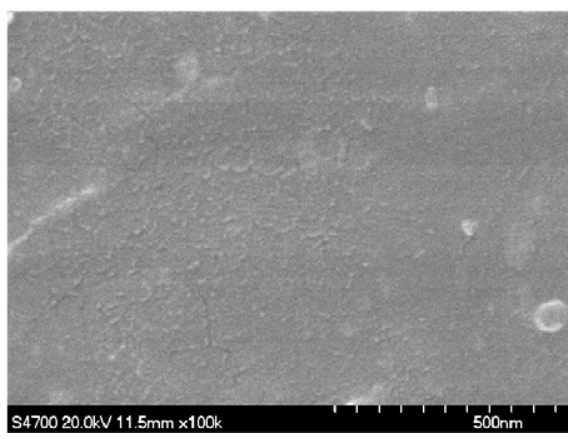

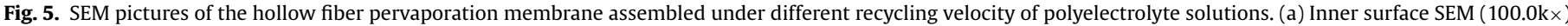

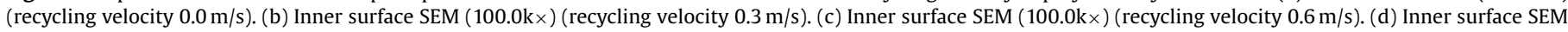

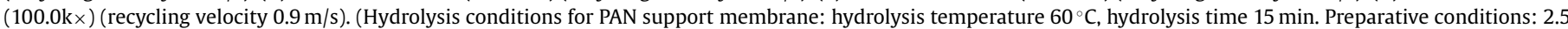
bilayers, dynamic negative pressure $-0.04 \mathrm{MPa}$, packing density $150 \mathrm{~m}^{2} / \mathrm{m}^{3}, 30 \mathrm{~min}$ filtration time, 0.05 wt.\% PAA aqueous solution, 0.25 wt.\% aqueous PEI solution, $25{ }^{\circ} \mathrm{C}$.) 


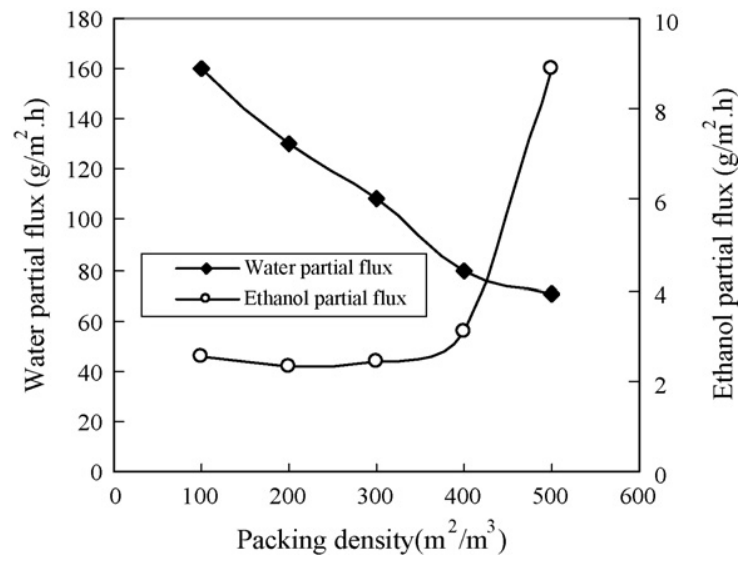

Fig. 7. Variations of water and ethonal partial fluxes with packing density of hollow fiber membrane module. (Hydrolysis conditions for PAN support membrane: hydrolysis temperature $60^{\circ} \mathrm{C}$, hydrolysis time $15 \mathrm{~min}$. Preparative conditions: 3.5 bilayers, dynamic negative pressure $-0.05 \mathrm{MPa}$, recycling velocity of polyelectrolyte solutions $0.3 \mathrm{~m} / \mathrm{s}, 30 \mathrm{~min}$ filtration time, $0.05 \mathrm{wt}$ \% PAA aqueous solution, $0.25 \mathrm{wt}$.\% aqueous PEI solution, $25^{\circ} \mathrm{C}$. Pervaporation conditions: feed temperature $50^{\circ} \mathrm{C}$, down-stream pressure $100 \mathrm{~Pa}$, EtOH content in feed solution $95 \mathrm{wt} . \%$.)

lead to the smaller space among the hollow fibers and narrower downstream vacuum channel. The increment of the vapour resistance in the permeate side could result in the decline of the total flux. Additionally, the higher mass transfer resistance in the boundary layer of the feed stream at lower feed velocity may cause the decrease in water flux [13-16]. However, a detailed investigation of concentration polarization is needed in the late study. Since the permeate vapour across membrane surface cannot be timely diffused away, the selectivity would be greatly negatively influenced, especially in the higher packing density cases. As we known, in pervaporation dehydration process, water component is able to preferentially pass through the membrane compared to ethanol component. However, the water flux decreased much more rapidly than alcohol flux did with the increase in packing density, which would lead to the decline of selectivity (Fig. 7). For example, the water and ethanol partial fluxes obtained from the packing density of $100 \mathrm{~m}^{2} / \mathrm{m}^{3}$ were $160.3 \mathrm{~g} / \mathrm{m}^{2} \mathrm{~h}$ and $2.5 \mathrm{~g} / \mathrm{m}^{2} \mathrm{~h}$, respectively. As a comparison, in the case of $500 \mathrm{~m}^{2} / \mathrm{m}^{3}$, those values were $71.1 \mathrm{~g} / \mathrm{m}^{2} \mathrm{~h}$ and $8.9 \mathrm{~g} / \mathrm{m}^{2} \mathrm{~h}$, respectively. In addition to the influences of diffusional resistances adjacent to the membrane, the mass transport itself is also a competitive process between ethanol and water molecules in pervaporation process. At the highest packing density of $500 \mathrm{~m}^{2} / \mathrm{m}^{3}$, the water flux decreased so quickly that it offered an opportunity for ethanol to pass through the membrane. Additionally, as the hollow fiber pervaporation module was prepared

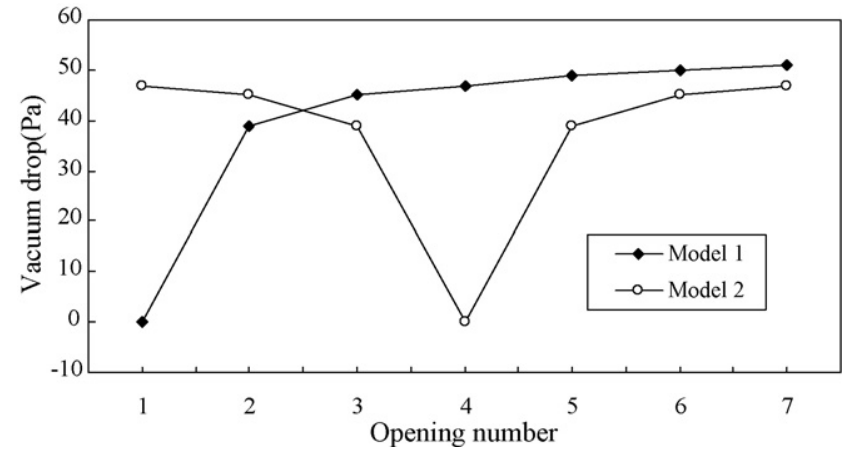

Fig. 9. Changes of vaccum drop along the hollow fiber during the pervaporation for $1 \mathrm{~m}$ length module. Model 1: one of the contact points of differential vacuum pressure gauge was always fixed at opening 1 while the other contact point was moved from opening 2 to opening 7. The vacuum drop between opening 1 and openings 2-7 was determined. Model 2: the middle opening (opening 4) was used as a fixed contact points where the other contact point changed from opening 1 to opening 3 and then from opening 5 to opening 7. The vacuum drops between opening 4 with the other openings were therefore determined.

using a dynamic LbL technique, even under the same dynamic negative pressure and recycling velocity of polyelectrolyte solution, the formation of selective layer was also affected by packing density. At the highest packing density of $500 \mathrm{~m}^{2} / \mathrm{m}^{3}$, a part of selective layer formed on hollow fibers might be not so dense and uniform because the hollow fibers are too compact. The SEM pictures, as shown in Fig. 8, compare the formation of selective layer under two typical packing densities including 100 and $500 \mathrm{~m}^{2} / \mathrm{m}^{3}$. It was noted that, even if the polyelectrolyte covers all the pores in both cases, the selective layer obtained from $500 \mathrm{~m}^{2} / \mathrm{m}^{3}$ was less uniform and dense than that obtained from $100 \mathrm{~m}^{2} / \mathrm{m}^{3}$. This also might possibly lead to ethanol flux increase at the highest packing density. Therefore, when designing hollow fiber pervaporation module, although the higher packing density enable production of modules at a lower cost per unit product, there should generally be a compromise between pervaporation efficiency and packing density because highly packing density module are usually not highly selective and permeable.

\subsection{Effects of fiber length}

As the pervaporation performance is very sensitive to the vacuum of the downstream side [17], a differential vacuum pressure gauge was used to measure the vacuum drop along the axial length of the module. Fig. 9 shows the vacuum drop along the axial direction of hollow fiber module. It was noted that the vacuum dropped sharply between the two openings near to the vacuum suction
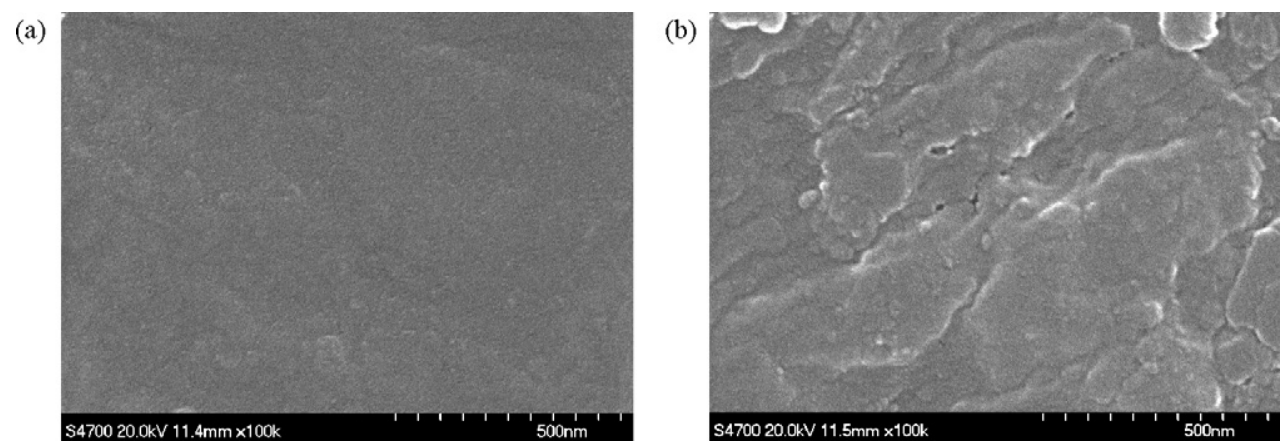

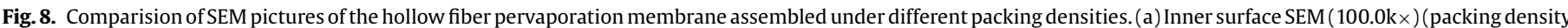

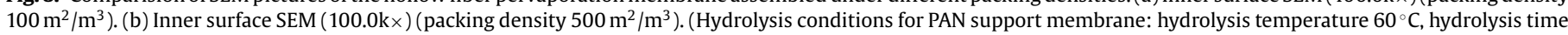

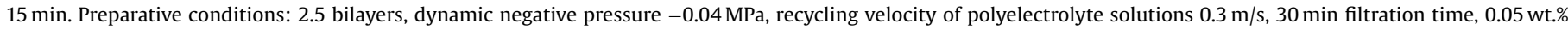
PAA aqueous solution, $0.25 \mathrm{wt}$.\% aqueous PEI solution, $25^{\circ} \mathrm{C}$.) 


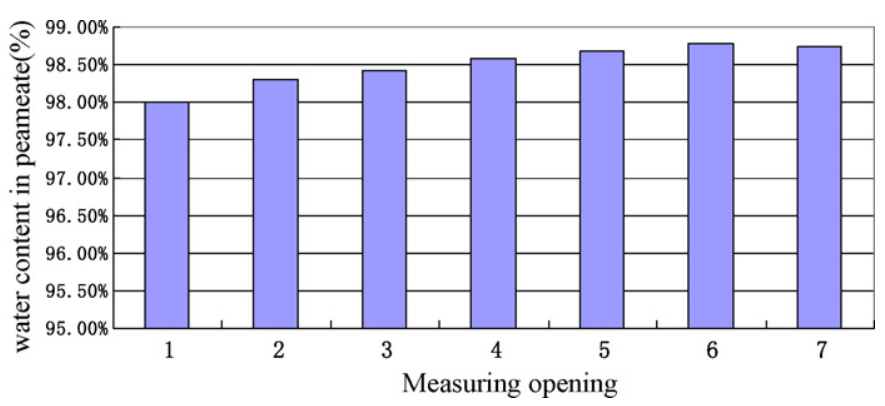

Fig. 10. Pervaporation performance at different suction openings. (Hydrolysis conditions for PAN support membrane: hydrolysis temperature $60^{\circ} \mathrm{C}$, hydrolysis time: $15 \mathrm{~min}$. Preparative conditions: 3.5 bilayers, dynamic negative pressure $-0.05 \mathrm{MPa}$, recycling velocity of polyelectrolyte solutions $0.3 \mathrm{~m} / \mathrm{s}$, packing density $100 \mathrm{~m}^{2} / \mathrm{m}^{3}$, $30 \mathrm{~min}$ filtration time, $0.05 \mathrm{wt}$.\% PAA aqueous solution, $0.25 \mathrm{wt}$.\% aqueous PEI solution, $25^{\circ} \mathrm{C}$. Pervaporation conditions: feed temperature $50{ }^{\circ} \mathrm{C}$, down-stream pressure $100 \mathrm{~Pa}$, EtOH content in feed solution $95 \mathrm{wt} . \%$.)

opening. For example, in model 1, the vacuum drop between opening 1 and opening 2 was $39 \mathrm{~Pa}$. A part of vacuum drop observed between openings 1 and 2 was probably due to entrance losses when the permeate vapour left the module and entered the suction tubing. After opening 3 (the length: $30 \mathrm{~cm}$ ), the vacuum drop was insignificant. Since the higher vacuum could result in better pervaporation performance, the results suggested that the most efficient fibers were adjacent to the vacuum suction opening. Similarly, it was noted from the curve obtained from model 2 that the most obvious vacuum drop occurred near to the vacuum suction opening (opening 4). Moreover, the symmetric drop was observed because the vacuum suction opening located in the middle of module. Another interesting phenomenon is that the vacuum drop between the outermost opening and vacuum suction opening in model 2 was lower than that in model 1 . This is because that the distance between the outermost opening and vacuum suction opening was rather shorter when the vacuum opening was in the middle of module. Therefore, the design of vacuum suction opening in the middle of module might be helpful to balance the vacuum drop of entire module and in turn benefit for pervaporation process. Additionally, the entire efficiency of hollow fiber pervaporation module might possibly be improved by alternating feed direction as we had previously proved this strategy was efficient to maximize efficiency of the entire hollow fiber ultrafiltration module [18]. Fig. 10 shows the pervaporation data determined by sucking the permeate from different openings using vacuum pump. As can be seen from Fig. 10, the selectivity of hollow fiber module could be maintained at a relatively high level even the fiber length increased to $1 \mathrm{~m}$. Additionally, the pervaporation capacity varied at a very narrow band. This suggested that the vacuum suction place had an insignificant effect on the entire selectivity for $1 \mathrm{~m}$ length module.

\section{Conclusions}

Since hollow fiber membrane module has been recognized as a cost-effective pervaporation type and in turn has great potential for industrial use, this study therefore conducted research into the preparation of pilot-scale hollow fiber pervaporation module. Inner skin modules were fabricated by alternatively depositing polycation and polyanion onto inner surface of hollow fiber support membranes under a pressure-driven process. It was noted that the formation of non-porous selective layer on the inner skin of hollow fiber was dependent on the dynamic negative pressure and recycling velocity of polyelectrolyte. High dynamic negative pressure would benefit for the formation of dense and compact layer. The higher circulating velocity of polyelectrolytes resulted in the stronger shear across the inner surface of hollow fiber mem- brane. Therefore, the nascent selective layers, to some extent, could be destroyed and in turn lead to the decline of selectivity. In the subsequent experiments, the effects of packing density of hollow fiber module were investigated by preparing the pilot-scale modules $(\Phi \times \mathrm{L}=1$ in. $\times 20 \mathrm{~cm})$ with different packing densities over the range of $100-500 \mathrm{~m}^{2} / \mathrm{m}^{3}$. It was noted that the packing density had great influences on the performance of hollow fiber pervaporation module. Both total flux and selectivity decreased with the increase in packing density. Therefore, packing density might be one of the most important contributing factors for the industrial hollow fiber module. Finally, the relatively high and stable selectivity could be obtained even the fiber length was increased to $1 \mathrm{~m}$. However, it was observed the sharp vacuum drop along the axial direction mainly occurred near to the suction opening. Therefore, in order to maximize the efficiency of the entire module, it is necessary to develop some new operation strategies during the pervaporation process, for example, designing middle vacuum suction opening or alternating feed direction, in the late study.

\section{Acknowledgements}

This work was supported by the Natural Science Foundation of Beijing (no. 8071001), the National Natural Science Foundation of China (nos. 20806001 and 20876003), the Beijing NOVA Programme (no. 2006B13), Beijing Municipal Science and Technology Planning Project (no. Z0605010000091), the Excellent Project for the Returned Overseas Chinese Scholars, Beijing Municipal Bureau of Personnel (no. 38005013200701) and Funding Project for Academic Human Resources Development in Institutions of Higher Learning Under the Jurisdiction of Beijing Municipality (no. PRH 200907105).

\section{References}

[1] B. Smitha, D. Suhanya, S. Sridhar, M. Ramakrishna, Separation of organic-organic mixtures by pervaporation-a review, J. Membr. Sci. 241 (2004) 1-21.

[2] P. Shao, R.Y.M. Huang, Polymeric membrane pervaporation, J. Membr. Sci. 287 (2007) 162-179.

[3] L.Y. Jiang, T.S. Chung, R. Rajagopalan, Dehydration of alcohols by pervaporation through polyimide Matrimid ${ }^{\circledR}$ asymmetric hollowfibers with various modifications, Chem. Eng. Sci. 63 (2008) 204-216.

[4] R.X. Liu, X.Y. Oiao, T.S. Chung, Dual-layer P84/polyethersulfone hollow fibers for pervaporation dehydration of isopropanol, J. Membr. Sci. 294 (2007) 103-114.

[5] R.X. Liu, X.Y. Qiao, T.S. Chung, The development of high performance P84 copolyimide hollow fibers for pervaporation dehydration of isopropanol, Chem. Eng. Sci. 60 (2005) 6674-6686.

[6] Y.L. Liu, C.H. Yu, L.C. Ma, G.C. Lin, H.A. Tsai, J.Y. Lai, The effects of surface modifications on preparation and pervaporation dehydration performance of chitosan/polysulfone composite hollow-fiber membranes, J. Membr. Sci. 311 (1-2) (2008) 243-250.

[7] Y. Wang, S.H. Goh, T.S. Chung, P. Na, Polyamide-imide/polyetherimide duallayer hollow fiber membranes for pervaporation dehydration of $\mathrm{C1}$-C4 alcohols, J. Membr. Sci. 326 (2009) 222-233.

[8] F. Zhou, W.J. Koros, Pervaporation Using hollow-fiber membranes for dehydrating acetic acid and water mixtures, Ind. Eng. Chem. Res. 45 (2006) 1787-1796.

[9] T.C. Bowen, H. Kalipcilar, J.L. Falconer, R.D. Noble, Noble pervaporation of organic/water mixtures through B-ZSM-5 zeolite membranes on monolith supports, J. Membr. Sci. 215 (2003) 235-247.

[10] G. Zhang, X. Song, S. Ji, N. Wang, Z. Liu, Self-assembly of inner skin hollow fiber polyelectrolyte multilayer membranes by a dynamic negative pressure layer-by-layer technique, J. Membr. Sci. 325 (2008) 109-116.

[11] Z. Liu, G. Zhang, Y. Peng, S. Ji, The hollow fiber ultrafiltration membrane with inner skin and its application, Desalination 233 (2008) 55-63.

[12] D.M. Sullivan, M.L. Bruening, Ultrathin, cross-linked polyimide pervaporation membranes prepared from polyelectrolyte multilayers, J. Membr. Sci. 248 (2005) 161-170.

[13] R.O. Crowder, E.L. Cussler, Mass transfer resistances in hollow fiber pervaporation, J. Membr. Sci. 145 (1998) 173-184.

[14] S. Schnabel, P. Moulin, Q.T. Nguyen, D. Roizard, P. Aptel, Removal of volatile organic components (VOCs) from water by pervaporation: separation improvement by Dean vortices, J. Membr. Sci. 142 (1998) 129-141.

[15] S.X. Liu, M. Peng, L. Vane, CFD modeling of pervaporative mass transfer in the boundary layer, Chem. Eng. Sci. 59 (2004) 5853-5857. 
[16] M.G. Liu, J.M. Dickson, P. Cote, Simulation of a pervaporation system on the industrial scale for water treatment. Part I: Extended resistance-in-series model, J. Membr. Sci. 111 (1996) 227-241.

[17] C. Vallieres, E. Favre, D. Roizard, J. Bindelle, D. Sacco, New insights into pervaporation mass transport under increasing downstream pressure conditions: critical role of inert gas entrance, Ind. Eng. Chem. Res. 40 (6) (2001) 15591565.

[18] G. Zhang, Z.Z. Liu, L.F. Song, J.Y. Hu, S.L. Ong, W.J. Ng, Post-treatment of banknote printing works wastewater ultrafiltration concentration, Water Res. 38 (16) (2004) 3587-3595. 